\title{
Microstructural Evolution, Mechanical Properties and Thermal Stability of Gradient Structured Pure Nickel
}

\author{
Xiao $\mathrm{Li}^{1} \cdot$ Bo Guan ${ }^{2} \cdot$ Yun-Fei Jia ${ }^{1} \cdot$ Yun-Chang Xin ${ }^{2} \cdot$ Cheng-Cheng Zhang ${ }^{3} \cdot$ Xian-Cheng Zhang ${ }^{1}$. Shan-Tung Tu ${ }^{1}$
}

Received: 11 October 2018 / Revised: 2 December 2018 / Published online: 10 January 2019

(C) The Chinese Society for Metals (CSM) and Springer-Verlag GmbH Germany, part of Springer Nature 2019

\begin{abstract}
The microstructural evolution of pure nickel treated by deep rolling (DR) technique with different indent depths was investigated by means of optical microscopy and transmission electron microscopy. The surface roughness, hardness and residual stress distribution along the depth from surface were measured. Moreover, the DR-treated sample was annealed at temperatures from 300 to $700{ }^{\circ} \mathrm{C}$ for $2 \mathrm{~h}$. The results reveal that dislocation movements are the fundamental mechanisms of gradient grain refinement during the DR process. With increasing indent depth of the DR, the gradient microhardness on the cross section of sample significantly increases, the maximum compressive residual stress decreases, and the affecting region of residual stress increases. The results of thermal stability depict that the microstructure can be stable as temperature up to $300{ }^{\circ} \mathrm{C}$, and the abnormal grain growth and annealing twins are observed at $600{ }^{\circ} \mathrm{C}$.
\end{abstract}

Keywords Deep rolling $\cdot$ Pure nickel $\cdot$ Microstructural evolution $\cdot$ Mechanical properties $\cdot$ Thermal stability

\section{Introduction}

Failures of engineering materials often initiated from the surface, such as fatigue fracture, wear and corrosion. These failure modes are very sensitive to the surface structures and properties, which would determine the overall service life of the materials. Hence, surface modification techniques have been extensively used to improve the service life of mechanical components. Surface grain refinement techniques have attracted much attention for producing ultra-fined grain (UFG) or nanocrystalline (NC) as ultra-fined or nano-sized

Available online at http://link.springer.com/journal/40195

Yun-Fei Jia

yfjia@ecust.edu.cn

$\triangle$ Xian-Cheng Zhang

xczhang@ecust.edu.cn

1 Key Laboratory of Pressure Systems and Safety, Ministry of Education, School of Mechanical and Power Engineering,

East China University of Science and Technology, Shanghai 200237, China

2 School of Materials Science and Engineering, Chongqing University, Chongqing 400044, China

3 AECC Commercial Aircraft Engine Co. LTD, Shanghai Engineering Research Center for Commercial Aircraft Engine, Shanghai 201108, China grains in materials exhibit greatly enhanced strength [1], hardness [2], corrosion resistance [3], fatigue resistance [4] and other properties.

Various techniques, such as high-pressure torsion (HPT), surface mechanical attribution treatment (SMAT), surface mechanical grind treatment (SMGT) and deep rolling (DR), have been applied to obtain refined grains. The technique of DR was used in the present study due to its advantages of generating work hardening and compressive residual stress in deformed surface layer, as well producing the glossy surface [5]. Thus, the mechanical properties of the materials treated by DR process could be enhanced significantly. The effects of DR on fatigue behavior have been thoroughly investigated. The surface layer with a low surface roughness, work hardening, and an increment in strength or hardness had a good resistance to fatigue crack initiation. After the formation of fatigue crack, the rate of fatigue crack propagation was retarded by the pronounced compressive residual stress [6]. It was well known that the DR technique has been successfully used in the industrial and biomedical fields [7], including crankshafts, turbine blades in the power plant, surgical implants.

Pure nickel was recognized as the most suitable material for the applications in the electrothermal actuator [8], thermocouple sheath [9] and heat exchanger [10]. And, it was also an ideal material as a protective coating on the 
inside surface of nuclear steam generator tubes due to its high resistance to stress corrosion cracking [11]. However, the low hardness and strength of the pure nickel must be improved to increase the applicability. The mechanical properties and microstructural evolution of pure nickel processed by HPT, ECAP and SMGT have been investigated in recent years. Luo et al. [12] found the microstructure of polycrystalline nickel contained dislocation cells, microbands and cell blocks at the low strain, while the cell blocks evolved into the lamellar structure at the high strain when subjected to dynamic plastic deformation (DPD). Zhilyaev et al. [13] pointed out that the dislocation movement was the main deformation mechanism of pure polycrystalline nickel due to its high stacking fault energy. Zhilyaev et al. [14] also found that the three main deformation mechanisms occurred in ultra-fine-grained nickel after being processed by HPT and ECAP techniques, i.e., dislocation slip, a rotation mode of deformation and dynamic recovery. Liu et al. [15] obtained a 2D nanometer-scale laminated (NL) surface structure of nickel as subjected to SMGT, which gave the specimen extraordinary mechanical properties. However, very few studies focused on the microstructural evolution and mechanical properties of gradient structured nickel processed by DR.

Additionally, Fong et al. [16] and Tsuji et al. [17] have focused on post-deformed annealing to achieve the best combination of strength and plasticity. And, the gradient structure usually becomes unstable at elevated temperatures. Thus, it was necessary to investigate the thermal stability of the gradient structured materials for the further application. In contrast to wide studies on the microstructure and mechanical properties of the UFG nickel and its alloys [18], the thermal stability has rarely been addressed.

In this study, the microstructures and mechanical properties of the gradient structured pure nickel processed by different indent depths of the DR were analyzed; especially, the thermal stability of the gradient structured pure nickel was also studied.

(a)

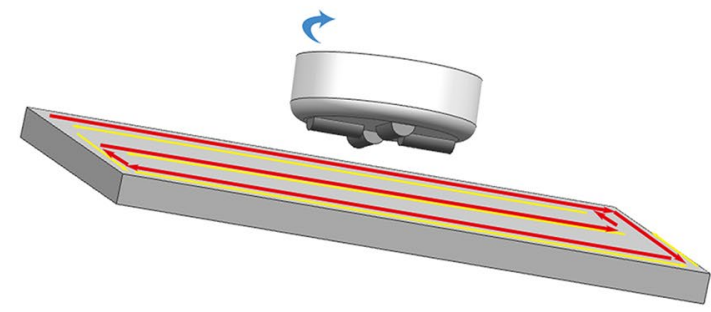

\section{Experimental}

The material used in this study was the annealed pure nickel (N4) with the following chemical composition (wt\%): C-0.109, P-0.009, S < 0.001, Cu-0.008, Fe-0.018, Si-0.031, $\mathrm{Mn}-0.023, \mathrm{Zn}<0.001$ and balance nickel. All of the specimens were mechanically polished with sandpaper. And then, the specimens with the size of $70 \mathrm{~mm} \times 50 \mathrm{~mm} \times 6 \mathrm{~mm}$ were subjected to the deep rolling (DR) processing. The DR procedure is schematically depicted in Fig. 1. A rolling cutter was forced into the specimen surface with $20 \mu \mathrm{m}$ in each pass at the ambient temperature. The temperature of the specimens during the DR process was controlled by cooling oil.

In order to effectively refine grains, the specimen was rolled by multiple passes. Four accumulative indent depths of 100, 200, 300 and $400 \mu \mathrm{m}$ (specimen 1-4) were selected for the DR process in this work. The rotation velocity $\left(V_{1}\right)$ and the feed velocity $\left(V_{2}\right)$ of the rolling cutter were 132 $\mathrm{r} \mathrm{min}^{-1}$ and $0.15 \mathrm{~mm} \mathrm{~s}^{-1}$, respectively. After the DR process, the cross-sectional metallographical specimens were ground using 180-, 400-, 800-, 1200- and 2000-grit papers. Afterward, the specimens were polished using $1 \mu \mathrm{m}$ diamond solution and etched in a solution of $5 \mathrm{ml} \mathrm{H}_{2} \mathrm{O}+18 \mathrm{ml}$ $\mathrm{HNO}_{3}+50 \mathrm{ml} \mathrm{CH}_{3} \mathrm{COOH}$ for $15 \mathrm{~s}$. The microstructure was investigated by Alm zeiss optical microscopy (OM) and transmission electron microscopy (TEM, JEOL JEM-2100, Japan) with an accelerating voltage of $200 \mathrm{kV}$. The thin foils at different depths from surface for TEM observation were cut paralleling to the treated surface and mechanically polished to a thickness of $30 \mu \mathrm{m}$. Finally, the thin foils were thinned by a twin-jet polishing technique in an electrolyte of $15 \mathrm{ml} \mathrm{HCLO}_{4}+285 \mathrm{ml} \mathrm{CH}_{3} \mathrm{COOH}$ at a voltage of $50 \mathrm{~V}$ and a temperature of about -20 to $-30{ }^{\circ} \mathrm{C}$.

Three-dimensional non-contact optical profilometer (IFM G4) was used for quantitative analysis of surface morphology. For each specimen, the surface roughness at five separate locations was measured. The microhardness was measured using a micro-Vickers hardness tester (HXD-1000TM) at a load of $50 \mathrm{~g}$ and a dwell time of $15 \mathrm{~s}$. The distance

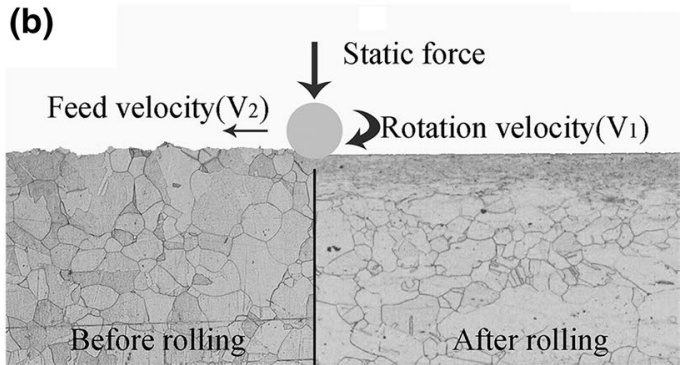

Fig. 1 Schematic illustrations of the roller and sample $\mathbf{a}$; the deep rolling process $\mathbf{b}$ 
between successive indents was $20 \mu \mathrm{m}$ or more. The hardness at each condition was repeated five times. Residual stress along the depth of treated specimens was measured by Proto-I XRD MG40P FS STD with Mn-K $\alpha$ radiation and diffraction crystal plane for (311). The accelerating voltage was $20 \mathrm{kV}$. Because the residual stress measurement was sensitive to surface state, electrolytic polishing was used to remove the target surface layers. The measurements were repeated five times for each condition, and an average value was utilized. As well known, X-rays are diffracted from surface layers only. The measurement of stress distribution with depth requires removal of material to the desired depth. After the stressed layers are removed by electrochemical polishing, the successively measured stresses at different depths below the sample surface should be corrected by an amount proportional to the relaxation values created by the removed layers. Thermal stability studies were conducted in a muffle furnace. Isochronal annealing was carried out at temperatures from 300 to $700{ }^{\circ} \mathrm{C}$ for $2 \mathrm{~h}$ and cooled in the air.

\section{Results and Discussion}

\subsection{Microstructural Observation}

As shown in Fig. 2, a gradient microstructure along the depth from sample surface was generated, which was due to a gradient strain induced by the DR process. A larger accumulative indent depth of the DR process induced a thicker deformed layer. However, some small cracks were found on the top surface layer of specimen-4 (Fig. 2d), which could be resulted from the shedding of surface material during deep rolling. Thus, a larger indent depth cannot be performed on the present material in this study.

The gradient layer could be manually subdivided into three different regions (Fig. 2c): (i) a severely deformed layer on the surface. Almost all grains were significantly refined and can hardly be identified by OM; (ii) a transitional layer affected by the shear deformation. The grains were elongated slightly, and some grain boundaries were blurred and curved; and (iii) the matrix retained equiaxed and coarse grains with regular grain boundaries. The thickness of the deformation layer was strongly dependent on the indent depth.

In order to further investigate the microstructural evolution of gradient structured nickel, TEM observations were carried out on the top surfaces of four typical samples. As shown in Fig. 3a, for the sample rolled with indent depth of $100 \mu \mathrm{m}$, dislocation tangles (DTs) were formed in individual grain, as indicated by yellow arrows. During the DR processes, deformation took place both inside the grains and on the boundaries. Dense dislocation walls (DDWs) were also found in some regions. For the sample rolled with the indent depth of $200 \mu \mathrm{m}$, as shown in Fig. 3b, the microstructural features were similar with specimen-1. Moreover, coarse grains were subdivided into cell blocks with the size
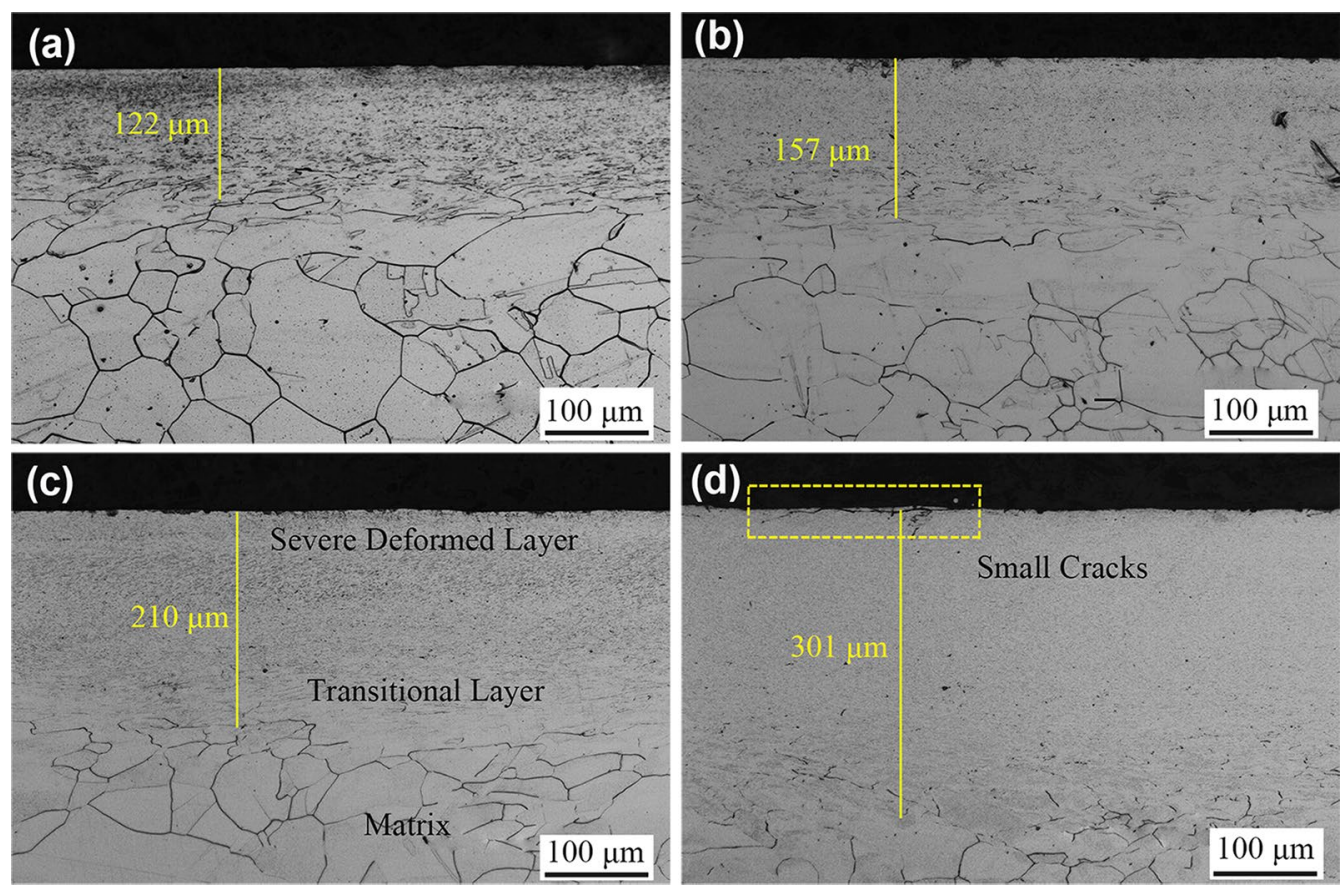

Fig. 2 Cross-sectional microstructures of the pure nickel treated by the DR with the indent depth of a $100 \mu \mathrm{m}, \mathbf{b} 200 \mu \mathrm{m}, \mathbf{c} 300 \mu \mathrm{m}, \mathbf{d ~} 400 \mu \mathrm{m}$, respectively 

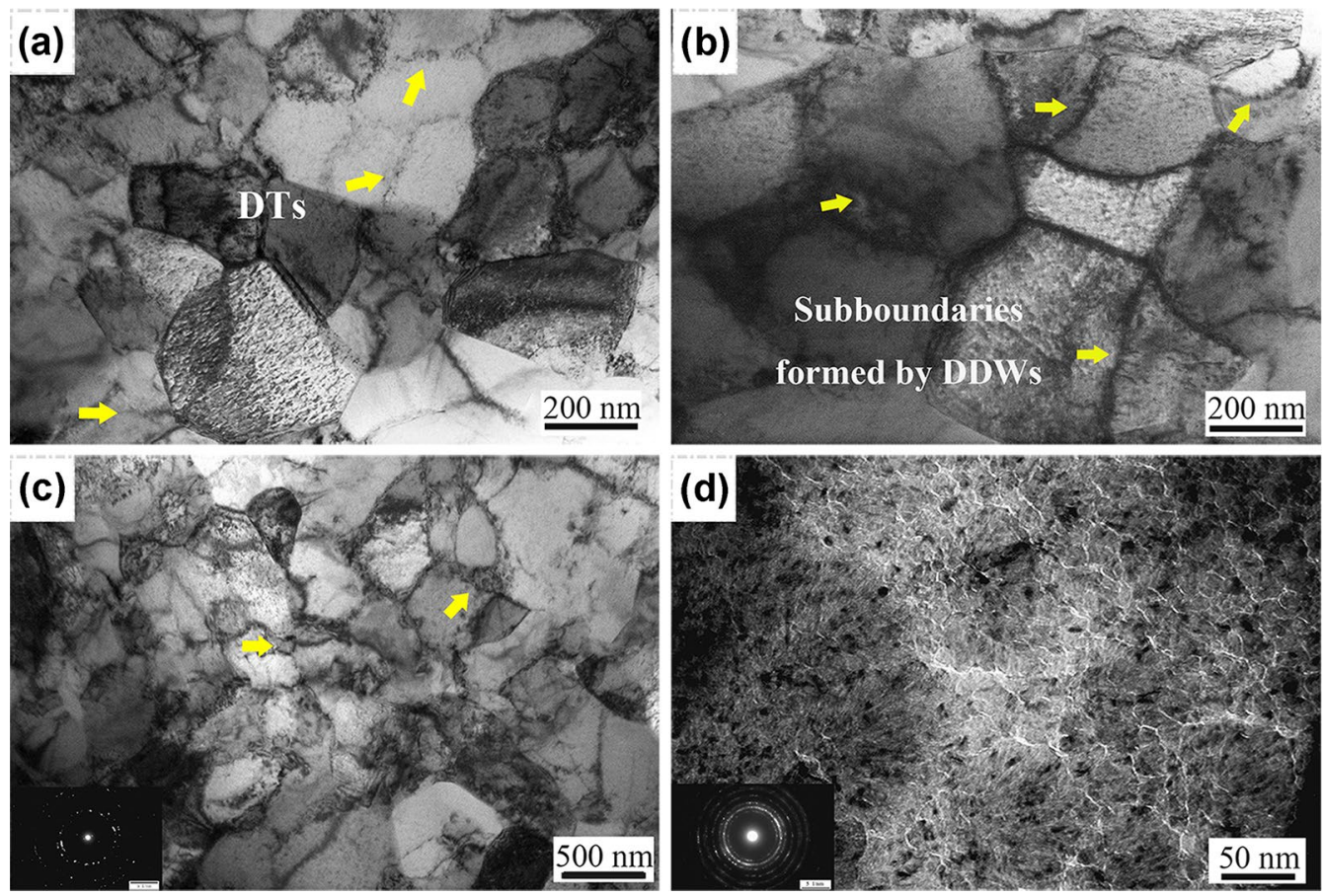

Fig. 3 TEM bright field images of the microstructures on top surface of a specimen-1, $\mathbf{b}$ specimen-2, $\mathbf{c}$ specimen-3, $\mathbf{d}$ specimen-4

of several hundred nanometers by DDWs [19]. The subboundaries were generated from several DDWs, to separate the individual grains. Figure $3 \mathrm{c}$ shows the TEM observation of the microstructures of the top surfaces of specimen-3. The formation of subgrains was obvious. Stretched and clustered diffraction spots along Debye rings were observed from the selected area electron diffraction (SAED) pattern, which suggested the subgrain microstructure with low-angle grain boundaries (LAGBs) and high-level internal stress formed [20]. The random orientations of the nanocrystallines may be resulted from the formation of high-angle grain boundary (HAGBs) or grain rotation under large strains at the top surface (Fig. 3d). The SAED patterns exhibited well-defined rings, which suggested that the nanocrystallines were highly disoriented with respect to each other.

As exhibited in Figs. 2 and 3, the specimen-4 experienced the most severe plastic deformation compared with the other three specimens with the best refinement effect. Hence, the TEM characterizations of the specimen- 4 at different depths were performed to identify the detailed microstructure evolution, as depicted in Fig. 4.

At depth of $\sim 300 \mu \mathrm{m}$, the dislocation configurations gradually resulted in the subdivision of original grains by forming dislocation cells (DCs), as shown in Fig. 4a. For coarse grains, plastic deformation was achieved mainly through continuous nucleation of dislocations from Frank-Read sources in the grain interiors and the glide motion of dislocations through the crystal lattice [21].
With increasing strain, dislocation walls and dislocation tangles were formed by the accumulating, annihilating and rearranging of numerous dislocations. These dislocation configurations gradually subdivided the coarse grains in the deformed layer by forming individual dislocation cells. Both the distance between the dislocation walls and the size of the dislocation cells decreased near the surface.

At the depth of $\sim 200 \mu \mathrm{m}$, as shown in Fig. 4b, DTs and DDWs transformed into subboundaries due to a higher strain level. It was reasonable to believe that these subboundaries were developed from DTs and DDWs by accumulation and annihilation of more dislocations [22]. Note that, for their higher latent energy, subboundaries could be the prior nucleation sites of new subgrains [23].

The typical microstructure at the depth of about $80 \mu \mathrm{m}$ from the treated surface is shown in Fig. 4c. With the strain continuously increasing, more dislocations were adsorbed and annihilated at the subboundaries. The intersections of subboundaries (yellow arrows in Fig. 4c) became more and more frequent, and thus, ultra-fined grains were formed among these subboundaries. The aspect ratio of subgrains increased with increasing strain, and the shape of subgrains became more regular [24]. It is well known that subgrains and dislocation cells were typically lowangle grain boundaries (LAGBs). With a further increase in strain, the LAGBs can be transformed into high-angle grain boundaries (HAGBs) [25]. 

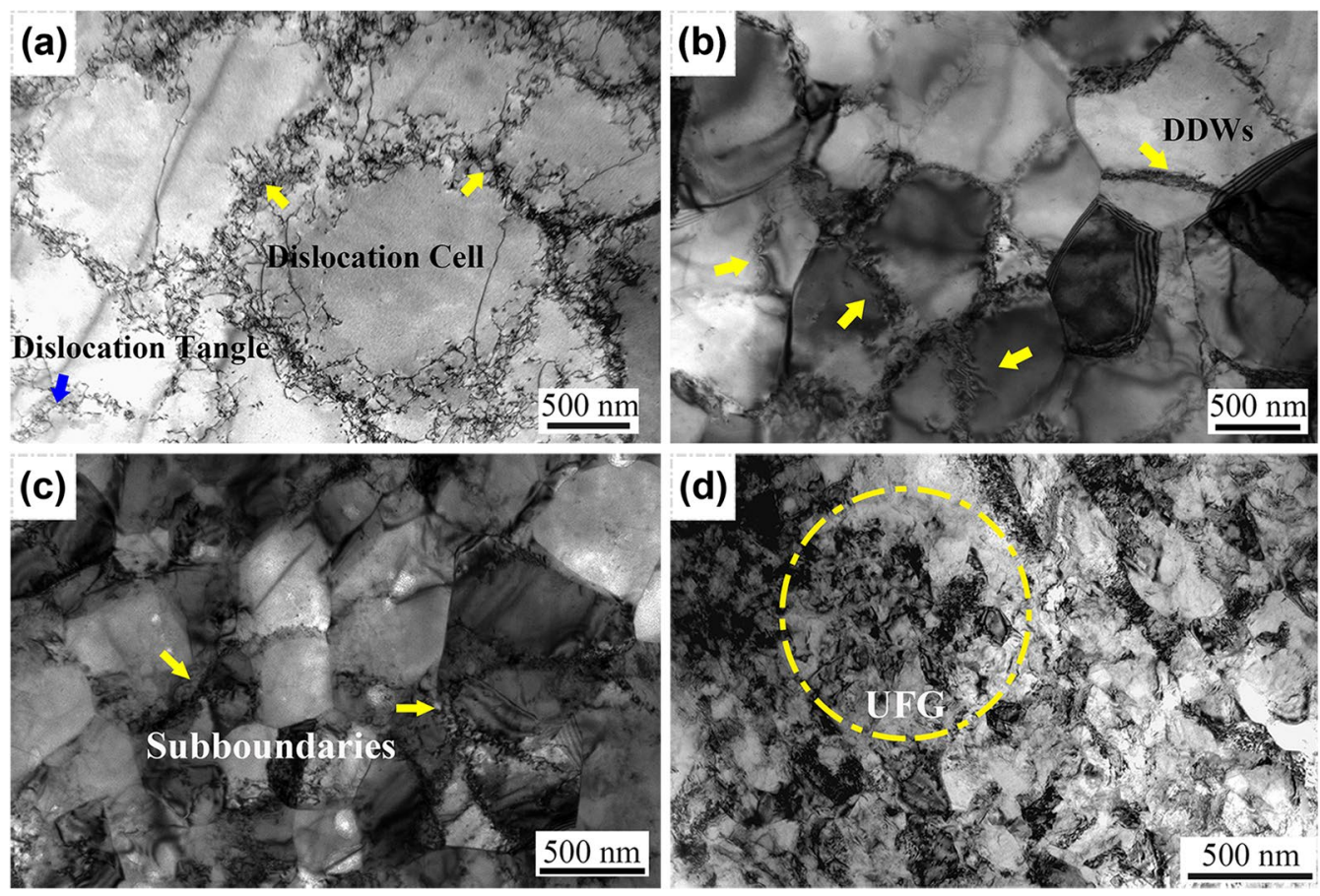

Fig. 4 TEM images at different depths from the top surface of the specimen-4: a at $\sim 300 \mu \mathrm{m}$ depth, showing that dislocation cells were formed; $\mathbf{b}$ at $\sim 200 \mu \mathrm{m}$ depth, showing that subboundaries were

formed to separate cells; $\mathbf{c}$ at $\sim 80 \mu \mathrm{m}$ depth, showing that subgrains were formed; $\mathbf{d}$ at $\sim 30 \mu \mathrm{m}$ depth, showing that roughly equiaxed ultra-fined grains were formed

As shown in Fig. 4d, at the depth of about $30 \mu \mathrm{m}$, the fraction of equiaxed ultra-fined grains increased and some nanocrystallines were formed. Those subboundaries transformed into conventional grain boundaries with large misorientations by accumulating more dislocations, and the orientations of grains became random [22].

Deformation strain increased drastically on the top surface layer, in which the orientations of grains with respect to their neighboring grains became completely random. Noted that the grain rotation and grain boundary sliding can be much easier for nano-sized grains with respect to the coarse ones [22]. Thus, equiaxed nanocrystallines with random orientation were readily formed, as shown in Fig. 3d. When the dislocations multiplication rate and annihilation rate reached an equilibrium, the increase in strain could not cause a continuous decline in grain size and the grain size reached a stabilized value [23].

Microstructural examinations showed a continuous evolution of the microstructure, which demonstrates that the dislocation movement was the key mechanism under the present condition, as schematically shown in Fig. 5. It was worthy to note that no deformation twins were found, which could be attributed to the unfavorable stress/strain state for twinning deformation during DR process. Dense dislocation walls, dislocation cells, subgrains and nanograins are typical microstructure features of the strengthened layers with indent depth of 100, 200, 300 and $400 \mu \mathrm{m}$, respectively. Moreover, the grain size decreased with increasing indent depth. The TEM results of the four specimens showed that the deformation layers produced by different indent depths had different microstructure features, as shown in Fig. 3.

\subsection{Mechanical Properties}

\subsubsection{Surface Roughness}

The surface morphologies could change significantly due to the severe contact between the cutter and metals. Figure 6 shows the variation in the surface roughness with the indent depth of the DR process. Obviously, with increasing indent depth, the surface roughness firstly decreased to a minimum value and then increased gradually. The minimum surface roughness existed within the accumulative indent depth of 100 and $200 \mu \mathrm{m}$. These findings indicated that surface roughness did not decrease monotonously with increasing indent depth of the DR. A moderate indent depth of the DR could improve the surface smoothness by removing the machined scratches, while the large indent depth may cause a detrimental effect on the surface by generating surface defects. 


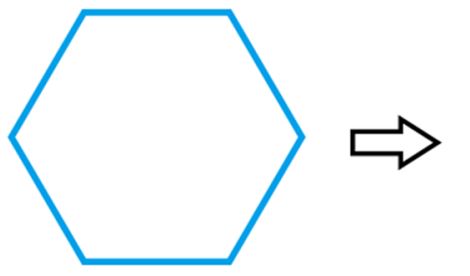

coarse grain

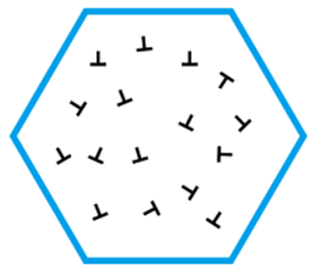

dislocation motion
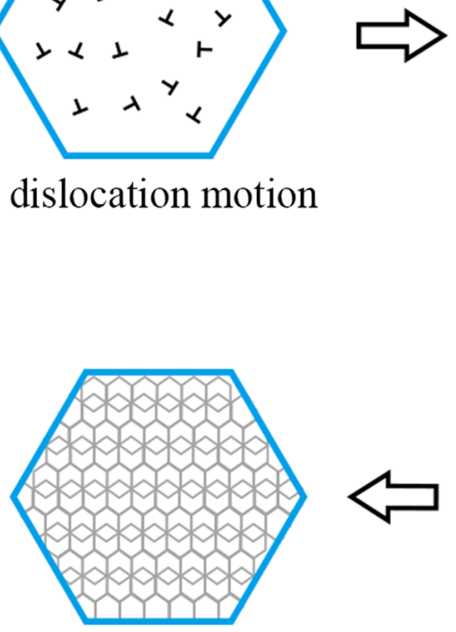

nano-grains

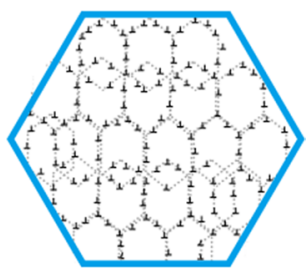

dislocation cells
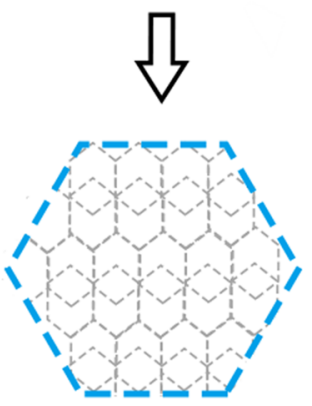

sub-micro grains

Fig. 5 Schematic illustration of the grain refinement process during the DR treatment

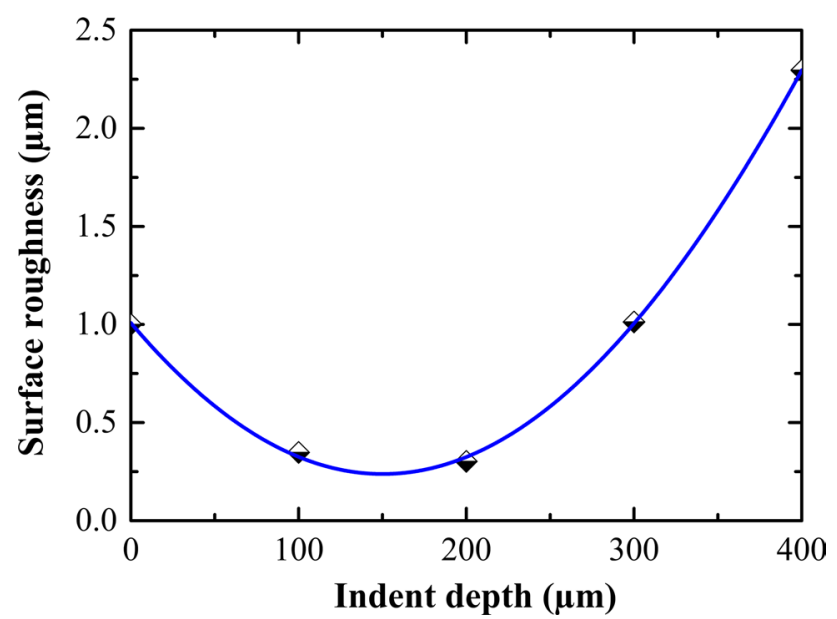

Fig. 6 Relationship between surface roughness and indent depth

\subsubsection{Hardness}

Figure 7 displays the cross-sectional microhardness distribution along the depth from the top surface. It was evident that a gradient hardening behavior occurred in the four specimens. With the distance close to the sample surface, the hardness gradually increased. The hardness of specimen-1 increased from $115 \mathrm{HV}$ (the hardness of nickel before DR) to $175 \mathrm{HV}$, while that of specimen-4 from 115 to $220 \mathrm{HV}$. These findings suggested that a larger indent depth of the DR process induced a higher hardness. That is, a severe plastic deformation resulted in a more significant surface hardening

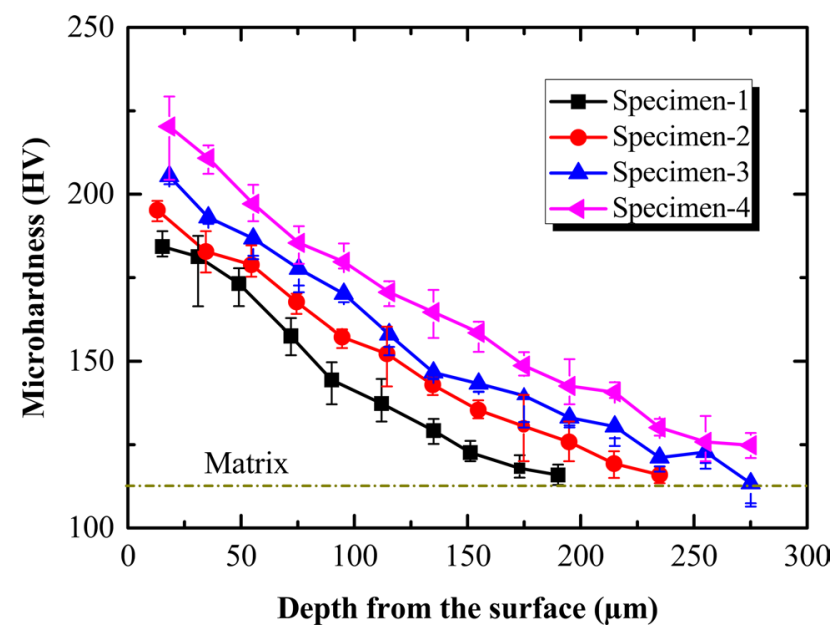

Fig. 7 Variation in the microhardness with the depth form surface for the four specimens

phenomenon. Because plastic deformation was caused by the motion of dislocations, the strengthening mechanism was to introduce some barriers to impede dislocation motion. The barriers can be dislocations, solid solutes, second phase particles and grain boundaries (GBs). GBs were particularly strong barriers to dislocation motion, because dislocations could not directly pass through GBs. The enhanced grain boundaries strengthening by grain refinement and the enhanced strain hardening due to the increase in lattice defects could account for the increase in the hardness of these specimens. The grain refinement strengthening of 
DR-treated nickel is in accordance with the mechanisms reported in previous works $[13,26]$.

\subsubsection{Residual Stress}

The as-measured stress should be further corrected for that the relaxation and rearrangement of residual stress in the treated specimens due to electrolytic polishing are obtained by the following equation [26]:

$\sigma_{z}=\sigma_{z}^{\prime}+\left(\frac{1}{\delta-z}\right) \int_{0}^{z} \sigma_{\xi}^{\prime} \mathrm{d}_{\xi}-\left[\frac{\delta}{(\delta-z)^{2}}\right] \int_{0}^{z}\left(\frac{\delta-\xi}{2}\right) \sigma_{\xi}^{\prime} \mathrm{d}_{\xi}$,

where $\sigma_{z}^{\prime}$ is the measured residual stress, $\sigma_{z}$ is the corrected value, $\sigma_{\xi}^{\prime}$ is the measured residual stress distribution along depth from top surface to the removed plane thickness $z, \delta$ is the total thickness of the plane, $\xi$ is the integration variable.

Figure 8 shows the variation in the residual stress distribution with the distance away from the sample surface. Four parameters were named as: $\sigma_{\mathrm{s}}^{\text {crs }}$ was the compressive residual stress at the surface; $\sigma_{\mathrm{m}}^{\mathrm{crs}}$ was the maximum compressive residual stress; $Z_{0}$ was the depth at which compressive residual stress changed to tensile stress; and $Z_{\mathrm{m}}$ was the distance of $\sigma_{\mathrm{m}}^{\text {crs }}$ from the surface. The compressive residual stress was generated on the surface region and then increased to a maximum value at the subsurface. The maximum compressive residual stress, $\sigma_{\mathrm{m}}^{\mathrm{crs}}$, was at the subsurface instead of on the top surface. According to the Hertz contact theory [27], the maximum equivalent stress exists at a special depth beneath the surface, which could explain the phenomenon in the present study. $Z_{\mathrm{m}}$ increased with increasing indent depth. Furthermore, $Z_{0}$ was in the range of $[0, \sim 200 \mu \mathrm{m}]$, [0, $\sim 375 \mu \mathrm{m}],[0, \sim 400 \mu \mathrm{m}]$ and $[0, \sim 450 \mu \mathrm{m}]$ for specimen-1, specimen-2, specimen-3 and specimen- 4 , respectively. With

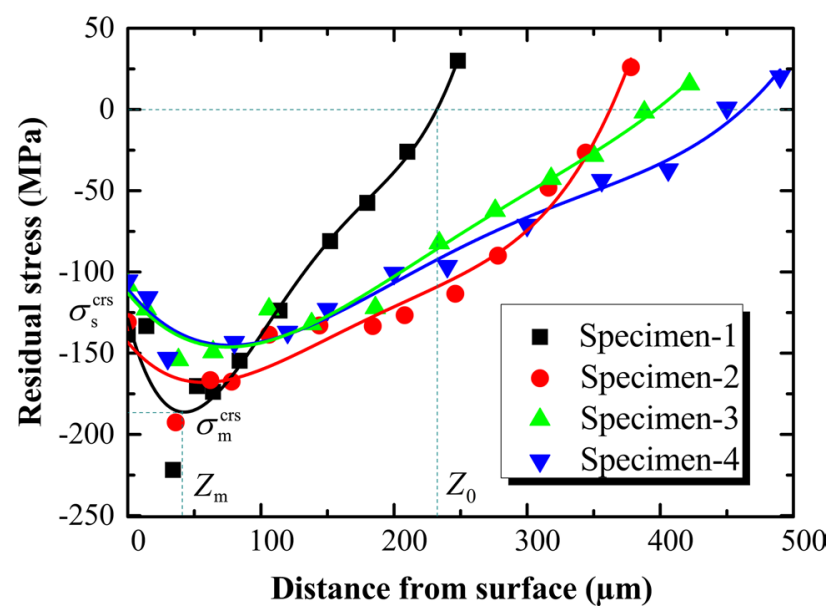

Fig. 8 Residual stress distribution along the depth from the surface for the four specimens increasing indent depth of the DR process, the affected region of compressive residual stress increased. This was because plastic deformation increased with increasing processing time, and the deformation layer became thicker and the larger strain gradient was formed along the depth. With continuously increasing the distance away from the surface, the compressive residual stress gradually decreased to zero and then became the tensile stress at the deeper location to ensure the equilibrium.

As shown in Fig. 8, the maximum compressive residual stress and the compressive residual stress on the surface decrease with increasing indent depth in specimen-1, specimen-2 and specimen-3, while the values basically keep invariable when the indent depth increased from 300 to $400 \mu$ m, i.e., from specimen- 3 to specimen- 4 , which indicates the residual stress goes stable after the indent depth increases to a certain value in this study. The finding was consistent with finite element results of shot peening process [28]. Actually, the maximum residual stress, $\sigma_{\mathrm{m}}^{\text {crs }}$, was affected by the repeatedly applied stress and stress relaxation during the rolling. Moreover, the applied stress and stress relaxation competed with each other. With the proceeding of the DR, the latter rolling process could cause the residual stress redistribution and relief, which could well explain why the residual stress decreased with an increased indent depth.

\subsection{Thermal Stability}

According to the Gibbs-Thomson classical grain growth theory [29], the driving force of grain growth increased with decreasing grain size. However, Chang et al. [30] and Zháňal et al. [31] illustrated that ultra-fined grains or even nanocrystallines presented a good thermal stability in practice. However, most of the investigations were based on the bulk ultra-fined grain material; very few studies focused on the gradient structured materials. Thus, it was essential to study the evolution of gradient structure of pure nickel with temperature. The gradient microstructure allowed various plastic deformation mechanisms of largely different microstructures to be activated concurrently. As a result, there was remarkable microstructural inhomogeneity throughout the thickness, which can potentially lead to different coarsening mechanisms. Thus, we investigated the top surface and the whole deformation layer by OM and TEM. If any area of grains starts coarsening, the instability of the gradient structure will be believed. To estimate the thermal stability of pure nickel obtained by the DR process (specimen-4), samples of specimen-4 were annealed for $2 \mathrm{~h}$ at the temperatures of $300,400,500,600$ and $700{ }^{\circ} \mathrm{C}$, respectively, and the microstructure of the surface layer with different annealing temperatures is shown in Fig. 9. At $300{ }^{\circ} \mathrm{C}$ (Fig. 9a), there was no obvious change in the deformed layer by optical microscopy. However, with increasing annealing 


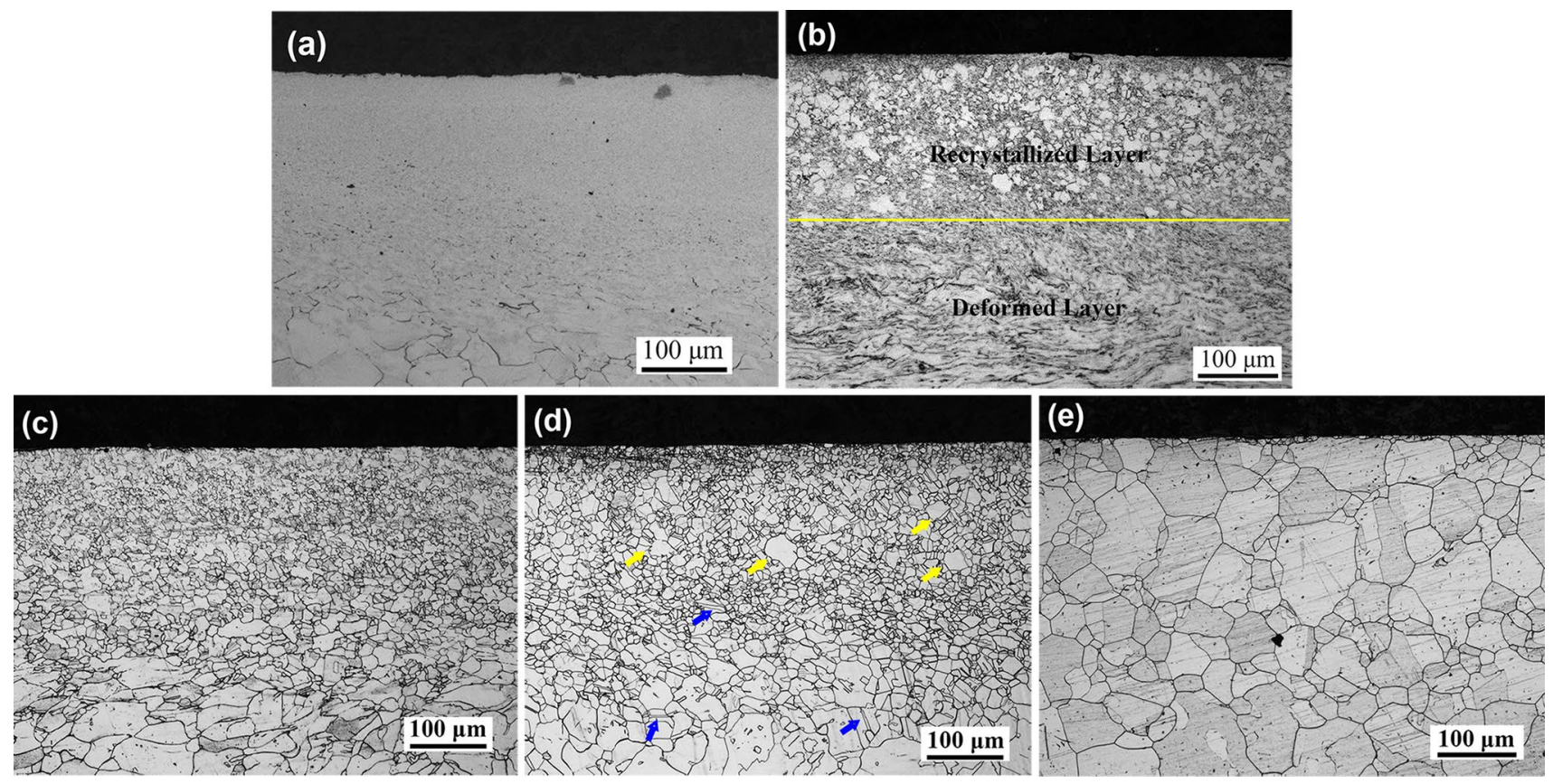

Fig. 9 Cross-sectional microstructures of specimen- 4 annealed at $300{ }^{\circ} \mathrm{C} \mathrm{a}, 400{ }^{\circ} \mathrm{C} \mathrm{b}, 500{ }^{\circ} \mathrm{C} \mathrm{c}, 600{ }^{\circ} \mathrm{C} \mathrm{d}, 700{ }^{\circ} \mathrm{C} \mathrm{e}$ for $2 \mathrm{~h}$, respectively

temperature, the surface grains grew up gradually, as shown in Fig. 9b-e. At $600^{\circ} \mathrm{C}$, abnormal growth of a few grains took place. Some new large grains as pointed out by yellow arrows in Fig. 9d were considered to be the grains with abnormal grain growth (AGG). Meanwhile, some annealing twins were also formed, as indicated by blue arrows. When the annealing temperature reached $700{ }^{\circ} \mathrm{C}$, as shown in
Fig. 9e, the size of refined grains grew up rapidly to several tens of micrometer. Moreover, the annealing twins disappeared at this temperature.

Microstructure of the gradient layers with the annealing time at different temperatures was further studied by TEM, and the results are shown in Fig. 10. The TEM views were located at the depth about $30 \mu \mathrm{m}$ from the top surface. The
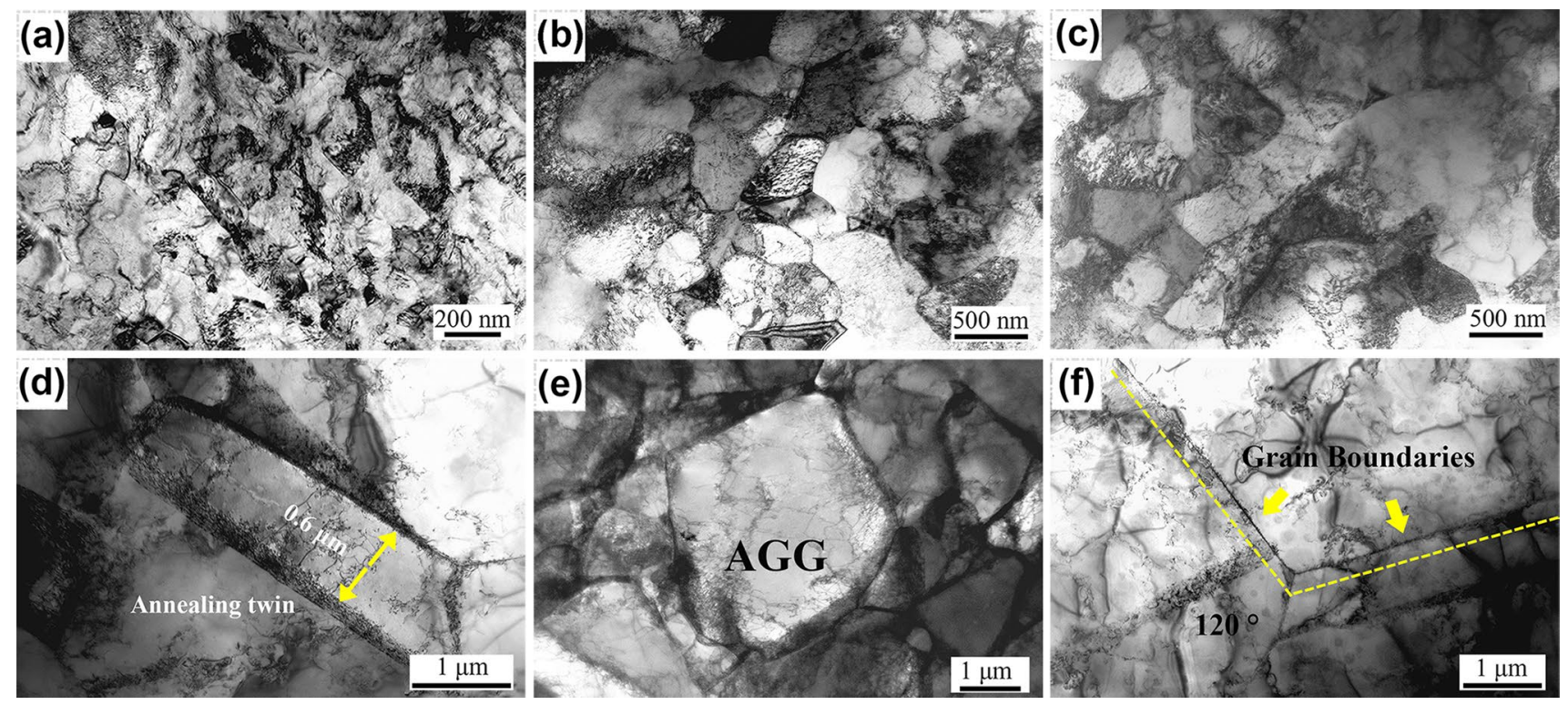

Fig. 10 TEM images of specimen- 4 at the depth of about $30 \mu \mathrm{m}$ annealed at $300{ }^{\circ} \mathrm{C} \mathbf{a}, 400{ }^{\circ} \mathrm{C} \mathrm{b}, 500{ }^{\circ} \mathrm{C} \mathrm{c}, \mathbf{d}, 600{ }^{\circ} \mathrm{C} \mathrm{e,}, 700{ }^{\circ} \mathrm{C} \mathbf{f}$ for $2 \mathrm{~h}$, respectively 
microstructure of the specimen annealed at $300{ }^{\circ} \mathrm{C}$ for $2 \mathrm{~h}$ (Fig. 10a) did not show obvious changes in comparison with that before annealing (Fig. 4d), except that the internal dislocation density declined slightly. This phenomenon was consistent with findings by Schafler and Pippan's [32], in which the dislocation density of the pure nickel processed by HPT reduced from $7.5 \times 10^{15} \mathrm{~m}^{-2}$ before annealing to $1.5 \times 10^{15} \mathrm{~m}^{-2}$ after annealing for $1 \mathrm{~h}$ at $245^{\circ} \mathrm{C}$. The grains with low dislocation density and thin straight boundaries were the characteristic of the recovery state. Grain coarsening started at annealing temperature up to $400{ }^{\circ} \mathrm{C}$, which was characterized by a recrystallized structure (Fig. 10b). Annealing at a higher temperature could lead to the disappearance of the small grains, and the grain size increased with temperature rising. Raising the annealing temperature to $500{ }^{\circ} \mathrm{C}$ (Fig. 10c) could cause a structural evolution in a heterogeneous way. The recrystallization proceeded, and the microstructure was composed of the roughly equiaxed grains. At this temperature, annealing twins were formed, which were also observed at $600{ }^{\circ} \mathrm{C}$ (Fig. 10d). In addition, the abnormal grain growth was observed at $600{ }^{\circ} \mathrm{C}$. The large grains were formed by the abnormal grain growth, and the small grains were formed by recrystallization. The stored energy introduced by the DR process may be the dominant factor determining the abnormal grain growth [33]. Actually, the distribution of stored energy was not homogenous in the deformed layer. Thus, the nucleation and growth of some grains with high stored energy could take place. Moreover, cube-oriented grains have a growth advantage to other grains [34]. Previous researches [35, 36] have shown that cube-oriented grains $(\{001\}<100>)$ in the cold deformed microstructure have large orientation gradients, which contribute to nucleation during subsequent annealing process. Moreover, due to the high migration mobility of cube grain boundaries, cube-oriented grains grew faster during postdeformed annealing process. We infer the abnormal grain growth in this study was related to the cube-oriented grains. The existence of large number of annealing twins could also promote the grain growth due to the energy reduction during annealing twinning [34]. As shown in Fig. 10e, most grains with the size of about several microns were formed when the specimen was annealed at $600{ }^{\circ} \mathrm{C}$. When the annealing temperature was up to $700{ }^{\circ} \mathrm{C}$, the microstructure was similar to that of the as-received state, as shown in Fig. 10f. The grain sizes grew up to several tens of microns, demonstrating that normal grain growth took place after recrystallization process. The annealing twins were annihilated at this temperature. Two factors can explain the phenomenon. Firstly, the low driving force in grain growth was insufficient to generate new annealing twins. Secondly, small grains containing twins were consumed by large grains, which grew without producing new twins [37]. Moreover, one can see coarse grains with well-defined straight boundaries and low energy triple junctions (Fig. 10f), which often have junctions of about $120^{\circ}$.

The thermal stability of pure nickel of approximately the same purity after the room temperature HPT was also studied [32], and a remarkable grain growth (average grain size increased to about $1 \mu \mathrm{m}$ ) was found when annealed at $418^{\circ} \mathrm{C}$ for $1 \mathrm{~h}$. The specimens were processed by dynamic channel angular pressing (DCAP) and $500{ }^{\circ} \mathrm{C}$ annealing, the structure was completely recrystallized, and grain sizes grew up to several tens of microns [38]. And the UFG microstructure produced by ECAP was significantly coarsened when annealed at $400{ }^{\circ} \mathrm{C}$ for $1 \mathrm{~h}$ [39]. It was noted that the annealing time chosen in this work was $2 \mathrm{~h}$, longer than that in the above references $(1 \mathrm{~h})$, and the grain size kept stable compared with the above experimental results, demonstrating that the thermal stability of pure nickel processed by the DR was better than some other SPD techniques. The evolution of annealing microstructure could be divided into several stages: a recovery process, a recrystallization process, homogeneous grain growth.

\section{Conclusions}

In this work, a gradient microstructure was fabricated using a deep rolling treatment on pure nickel. The microstructural evolution, mechanical properties and thermal stability under four different indent depths were studied. Several conclusions were summarized below.

(1) Gradient structure was formed in the surface layer of pure nickel. The accumulative indent depth has a significant effect on the microstructures and properties of the gradient structure. The microstructure evolution experiences three processes. At the early stage, dislocation cells were formed by the multiplication and arrangement of dislocations. Then, cell boundaries and DDWs were developed into subboundaries. Finally, the ultra-fined grains or nano-sized grains were formed.

(2) The accumulative indent depth had a significant effect on the surface roughness, microhardness and residual stress of the surface layer. Glossy surface was obtained when the accumulative indent depth was below $300 \mu \mathrm{m}$. With increasing indent depth of the DR, the overall microhardness significantly increases, the maximum compressive residual stress decreases, and the affecting region of residual stress increased.

(3) Thermal stability was investigated by post-isochronal annealing for $2 \mathrm{~h}$. The gradient microstructure was relatively stable below $300{ }^{\circ} \mathrm{C}$ and the grain coarsening in the form of recrystallization. Abnormal grain growth and annealing twins were observed during the recrystallization and grain growth process. 
Acknowledgements The authors would like to acknowledge gratefully for the financial support through the National Natural Science Foundation of China (Nos. 51725503, 51605164 and 51575183) and 111 Project. X.C. Zhang is also grateful for the support by Shanghai Technology Innovation Program of SHEITC (CXY-2015-001), Fok Ying Tung Education Foundation and Young Program of Yangtze River Scholars. Y.F. Jia is also grateful for the support by Shanghai Sailing Program (16YF1402300) and Shanghai Chenguang Program (16CG34).

\section{References}

[1] M. Dadashpour, R. Yeşildal, A. Mostafapour, V. Rezazade, J. Mech. Sci. Technol. 30, 667 (2016)

[2] H. Hamadache, Z. Zemouri, L. Laouar, S. Dominiak, J. Mech. Sci. Technol. 28, 1491 (2014)

[3] B.N. Mordyuk, O.P. Karasevskaya, G.I. Prokopenko, N.I. Khripta, Surf. Coat. Technol. 210, 54 (2012)

[4] J. Walker, D.J. Thomas, Y. Gao, J. Manuf. Process. 26, 419 (2017)

[5] S. Bagherifard, R. Ghelichi, M. Guagliano, Appl. Surf. Sci. 258, 6831 (2012)

[6] J. Muñoz-Cubillos, J.J. Coronado, S.A. Rodríguez, Int. J. Fatigue 95, 120 (2017)

[7] I. Altenberger, in 9th International Conference on Shot Peening, Paris (2005), p. 144

[8] A. Pimpin, I. Charoenbunyarit, W. Srituravanich, Sens. Actuators A Phys. 253, 49 (2017)

[9] X.Y. Zhong, X.Q. Wu, E.H. Han, X.B. Song, Eng. Fail. Anal. 17, $1404(2010)$

[10] C. Harris, M. Despa, K. Kelly, J. Microelectromech. Syst. 9, 502 (2000)

[11] G. Palumbo, F. Gonzalez, A.M. Brennenstuhl, U. Erb, W. Shmayda, P.C. Lichtenberger, Nanostruct. Mater. 9, 737 (1997)

[12] Z.P. Luo, H.W. Zhang, N. Hansen, K. Lu, Acta Mater. 60, 1322 (2012)

[13] A. Zhilyaev, S. Lee, G.V. Nurislamova, R. Valiev, T.G. Langdon, Scr. Mater. 44, 2753 (2001)

[14] A.P. Zhilyaev, B.K. Kim, G.V. Nurislamova, M.D. Baró, J.A. Szpunar, T.G. Langdon, Scr. Mater. 46, 575 (2002)

[15] X.C. Liu, H.W. Zhang, K. Lu, Science 342, 337 (2013)

[16] K.S. Fong, A. Danno, M.J. Tan, B.W. Chua, J. Mater. Process. Technol. 246, 235 (2017)
[17] N. Tsuji, Y. Ito, Y. Saito, Y. Minamino, Scr. Mater. 47, 893 (2002)

[18] R.Z. Valiev, Mater. Sci. Eng. A 234-236, 59 (1997)

[19] X.C. Liu, H.W. Zhang, K. Lu, Scr. Mater. 95, 54 (2015)

[20] V.V. Popov, E.N. Popova, A.V. Stolbovskiy, V.P. Pilyugin, Mater. Sci. Eng. A 528, 1491 (2011)

[21] V. Yamakov, D. Wolf, S.R. Phillpot, A.K. Mukherjee, H. Gleiter, Nat. Mater. 1, 45 (2002)

[22] N.R. Tao, Z.B. Wang, W.P. Tong, M.L. Sui, J. Lu, K. Lu, Acta Mater. 50, 4603 (2002)

[23] M. Wen, G. Liu, J.F. Gu, W.M. Guan, J. Lu, Appl. Surf. Sci. 255, 6097 (2009)

[24] B. Bay, N. Hansen, D.A. Hughes, D. Kuhlmann-Wilsdorf, Acta Metall. 40, 205 (1992)

[25] N.P. Gurao, R. Kapoor, S. Suwas, Metall. Mater. Trans. A 41, $2794(2010)$

[26] W. Ting, W. Dongpo, L. Gang, G. Baoming, S. Ningxia, Appl. Surf. Sci. 255, 1824 (2008)

[27] V. Schulze, Modern Mechanical Surface Treatment: States, Stability, Effects (Wiley, Hoboken, 2003)

[28] L. Tan, D. Zhang, C. Yao, D. Wu, J. Zhang, J. Manuf. Process. 26, 155 (2017)

[29] L. Lu, N.R. Tao, L.B. Wang, B.Z. Ding, K. Lu, J. Appl. Phys. 89, $6408(2001)$

[30] H. Chang, I. Baker, Mater. Sci. Eng. A 476, 46 (2008)

[31] P. Zháňal, K. Václavová, B. Hadzima, Mater. Sci. Eng. A 651, 886 (2016)

[32] E. Schafler, R. Pippan, Mater. Sci. Eng. A 387-389, 799 (2004)

[33] J. Victoria-Hernández, J. Suh, S. Yi, J. Bohlen, W. Volk, D. Letzig, Mater. Charact. 113, 98 (2016)

[34] X.P. Chen, L.F. Li, H.F. Sun, L.X. Wang, Q. Liu, Mater. Sci. Eng. A 622, 108 (2015)

[35] P.P. Bhattacharjee, R.K. Ray, N. Tsuji, Acta Mater. 57, 2166 (2009)

[36] S. Zaefferer, T. Baudin, R. Penelle, Acta Mater. 49, 1105 (2001)

[37] Y. Jin, B. Lin, M. Bernacki, G.S. Rohrer, A.D. Rollett, N. Bozzolo, Mater. Sci. Eng. A 597, 295 (2014)

[38] V.V. Popov, E.N. Popova, D.D. Kuznetsov, Mater. Sci. Eng. A 585, 281 (2013)

[39] K. Sitarama Raju, M. Ghanashyam Krishna, K.A. Padmanabhan, V. Subramanya Sarma, N.P. Gurao, G. Wilde, J. Mater. Sci. 46, $2662(2011)$ 